\title{
The Importance of Theatre Therapy (Psychodrama) In the Treatment of Children and Adolescents with Autism Spectrum Disorder
}

\author{
Kaveh Moghaddam ${ }^{*}$, Aida Ravarian², Farhoud Saied Ershadi ${ }^{3}$, Ali Gorji ${ }^{4}$ \\ ${ }^{1}$ Private University of Alle Taha, Tehran, Iran \\ ${ }^{2}$ Pediatric Neurorehabilitation Research Center, University of Social Welfare and Rehabilitation Sciences, Tehran, Iran \\ ${ }^{3}$ University of Social Welfare and Rehabilitation Sciences, Tehran, Iran \\ ${ }^{4}$ Shefa Neuroscience Research Center, Khatam Alanbia Hospital, Tehran, Iran
}

Article Info:

Received: 11 Oct 2018

Revised: 18 Nov 2018

Accepted: 13 Jan 2018

\section{A BSTRACT}

Introduction: Children and adolescents with autism spectrum disorder are a group of children who suffer from odd and strange problems in the interpersonal relationship, social interaction with peer groups and others, verbal skills and daily living interests, and behaviors and movements. These problems can lead to several psychological and emotional disturbances in their family. Conclusion: Beside the rehabilitation, education and therapeutic interventions as well as art and music therapy, several investigations have shown that psychodrama or theatre therapy is a beneficial approach for the children with autism spectrum disorder associated with cognitive, perceptual and verbal function difficulties. The studies have shown that theatre therapy improves the symptoms of autism spectrum disorder in children. The present article discusses the importance of theatre and psychodrama in the treatment of children with autism spectrum disorder.

*Corresponding Author: Kaveh Moghaddam

E-mail:Dockm1358@yahoo.com

Key words:

1. Autism Spectrum Disorder

2. Psychodrama

3. Child

4. Adolescent 
اهميت تئاتردرمانى (سايكودراما) در درمان كودكان و نوجوانان مبتلا به اختلال طيف اوتيسم

$$
\begin{aligned}
& \text { كاوه مقدم':، آيداراوريان"، فرهود سعيد ارشادى"، على گرجى } \\
& \text { ادانشعاه غيرانتفاعى آل طه، تهران، ايران } \\
& \text { זمركز تحقيقات علوم اعصاب اطفال، دانشعاه علوم بهزيستى و توانبخشى، تهران، ايران } \\
& \text { سادانشخاه علوم بهزيستى و توانبخشى، تهران، ايران } \\
& \text { fامركز تحقيقات علوم اعصاب شفا، بيمارستان خاتمالانبيا، تهران، ايران }
\end{aligned}
$$

\section{اطلاعات مقاله:}

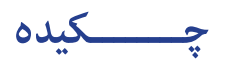

مقدمه: كودكان و نوجوانان مبتلا به اختلال طيف اوتيسم، گروهى از كودكان هستند كه از مشكلات

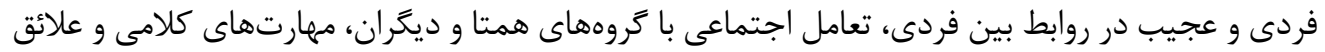

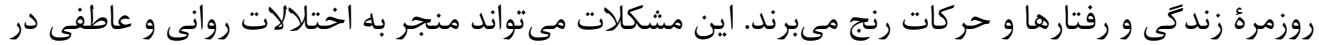

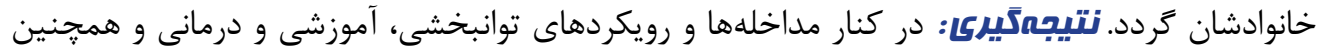

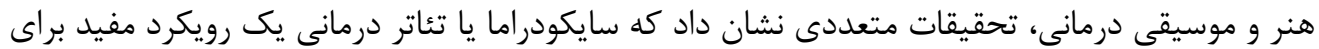

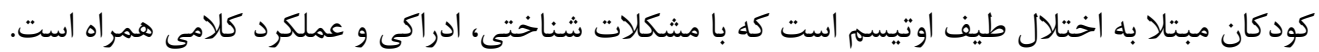

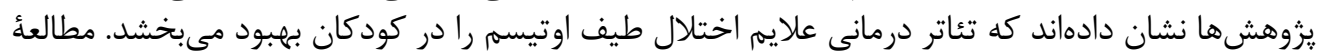

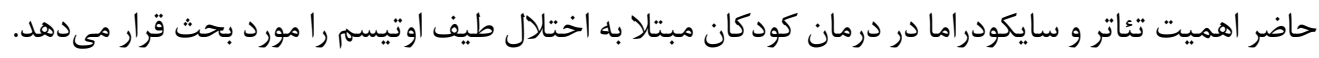

كليد وازمها:

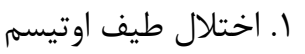

r.

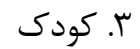

F

* نويسنده مسئول: كاوه مقدم

آدرس الكترونيكى: Dockm1358@yahoo.com 


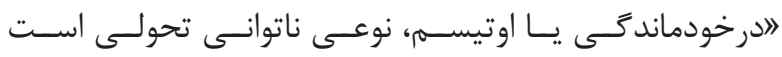

مقدمه

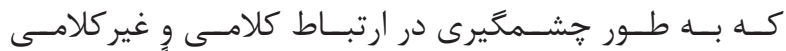

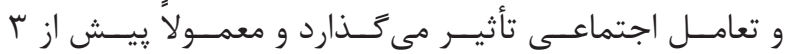

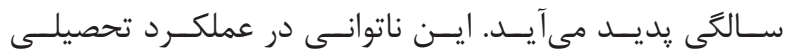

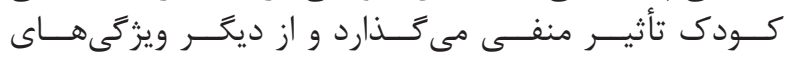

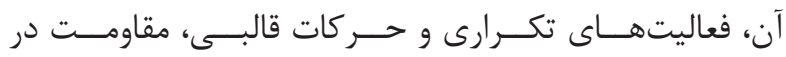

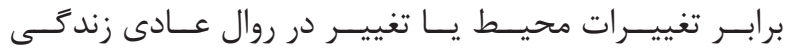

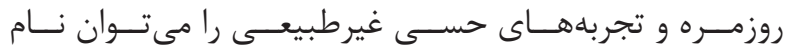

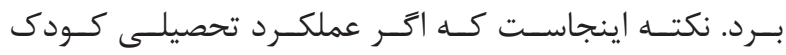

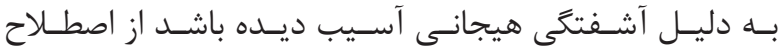

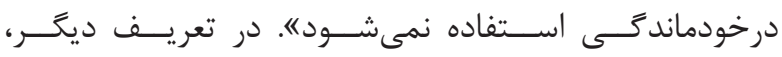

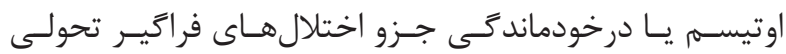

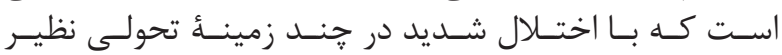

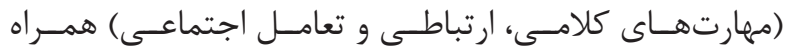

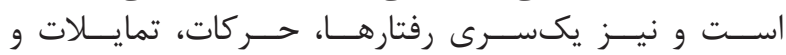

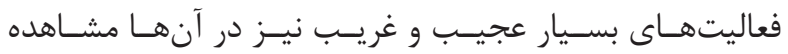

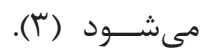

تأثير اختلال هاى طيف اوتيسم بر خانواده

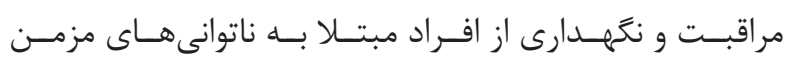

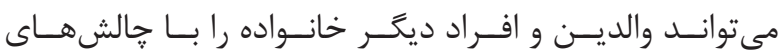

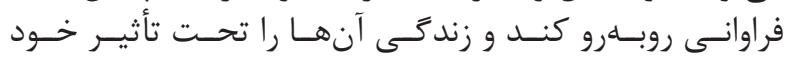

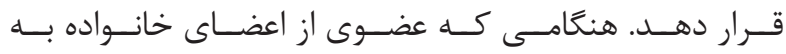

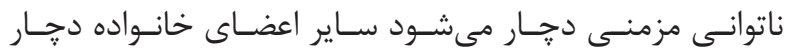

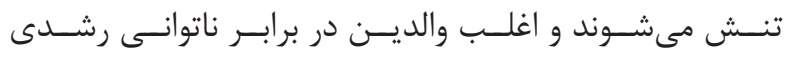

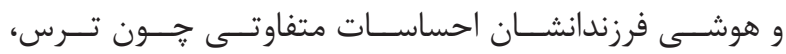

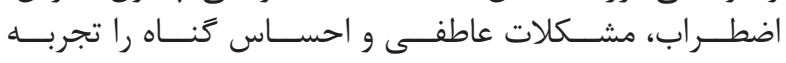

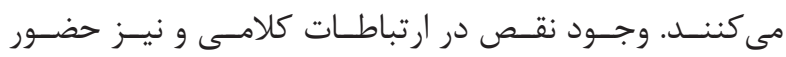

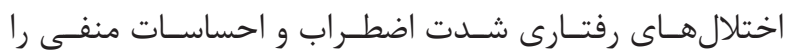
بيشــتر مى كنـــد.

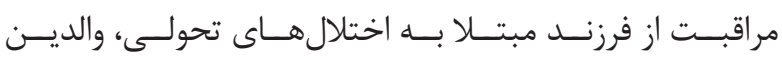

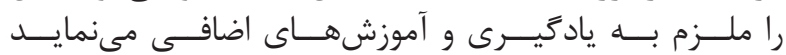

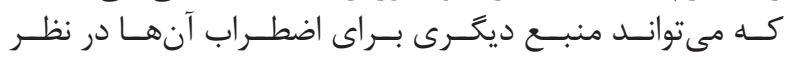

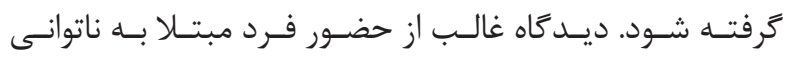

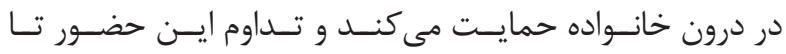

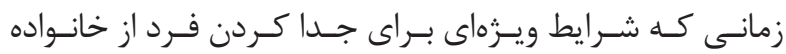

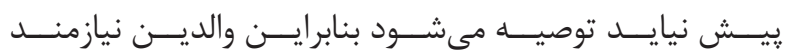

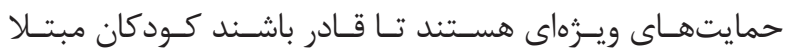

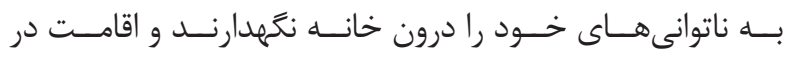

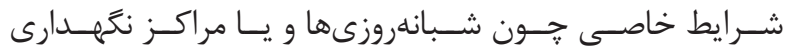

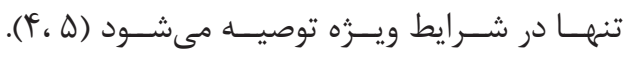

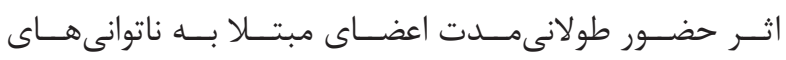

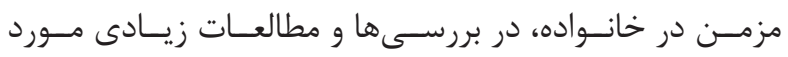

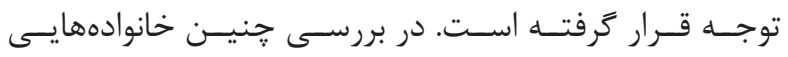

\author{
اختلالهاى طيف اوتيسم
}

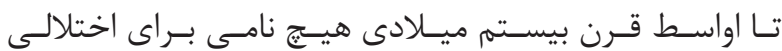

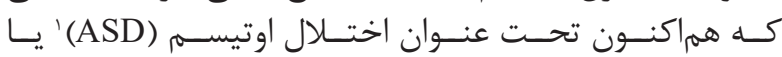

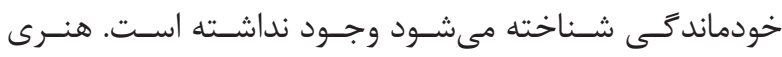

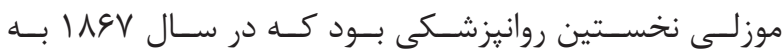

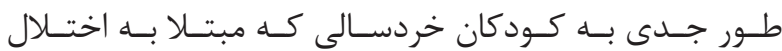

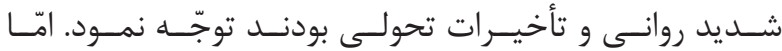

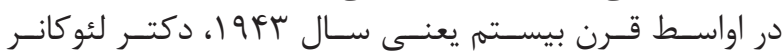

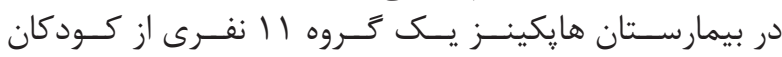

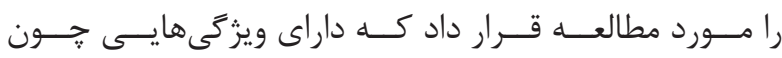

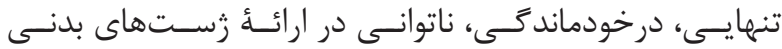

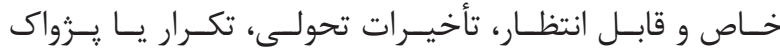

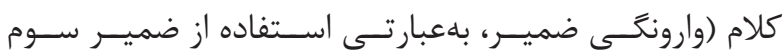

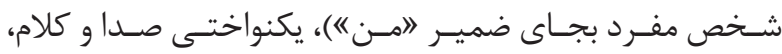

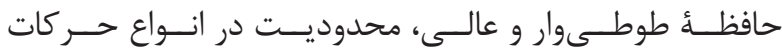

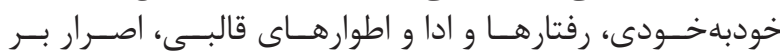

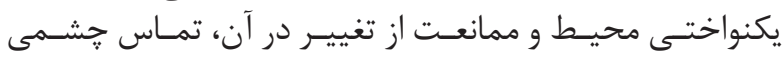

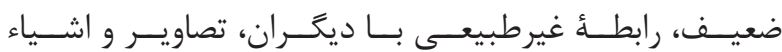

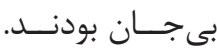

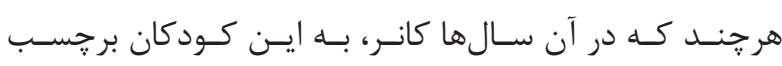

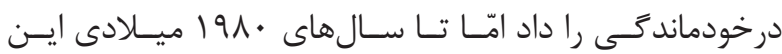

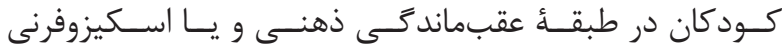

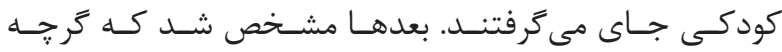

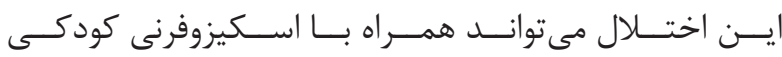

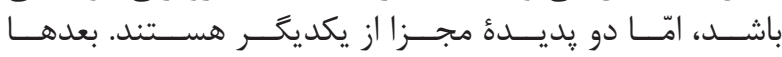

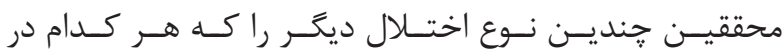

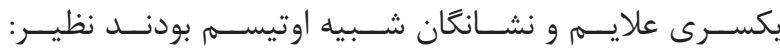

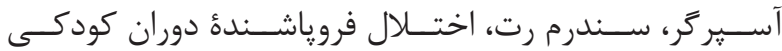

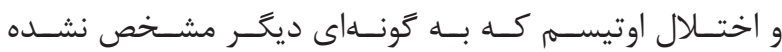

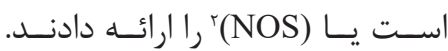

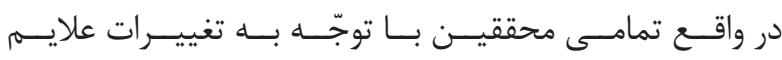

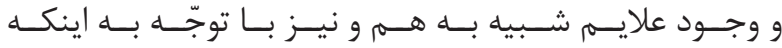

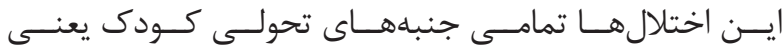

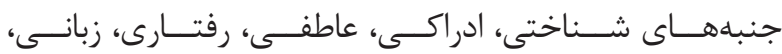

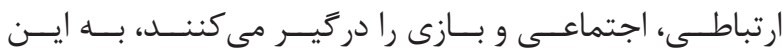

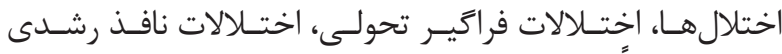

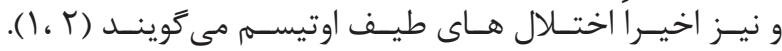
تعريف و علايم اختلال اصلاحيـهُ جديـد قانـون آمـوزش افـراد داراى ناتوانـى (IDEA)

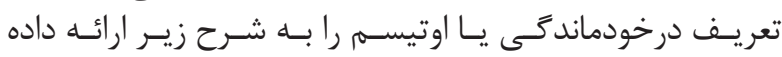
سـت:

${ }^{1}$ Autism spectrum disorder

${ }^{2}$ Not otherwise specified

${ }^{3}$ Individuals with disabilities education Act 
تئاتر درمانى (مقدمه و تعاريف)

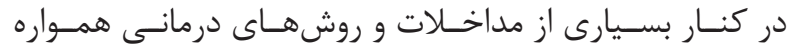

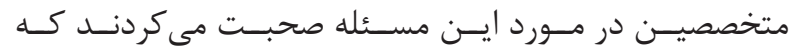

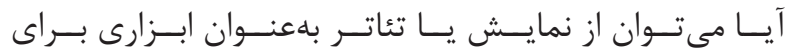

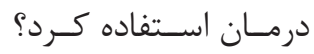

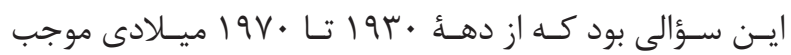

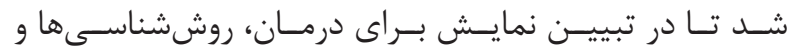

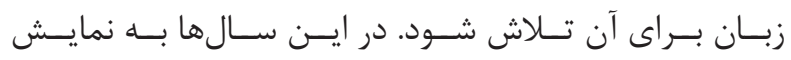

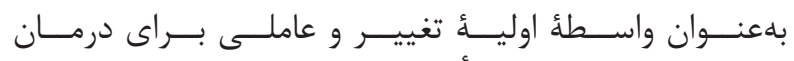
مشـكلات روانسى افـراد تأكيــد شـده اسـت

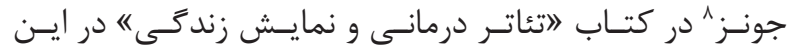

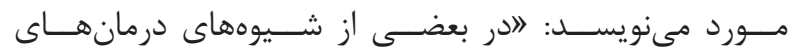

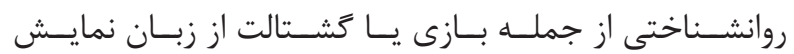

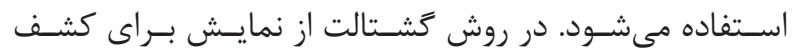

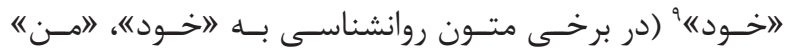

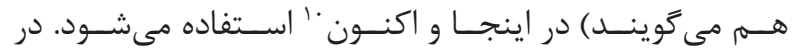

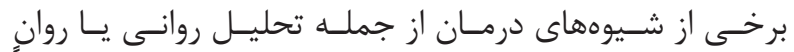

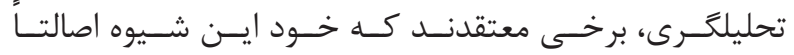

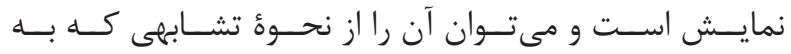

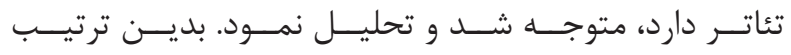

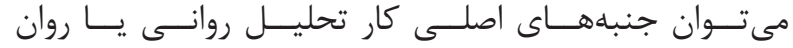

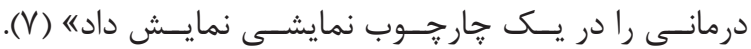

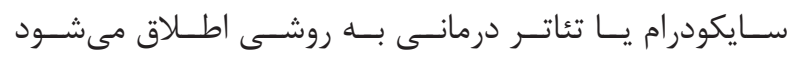

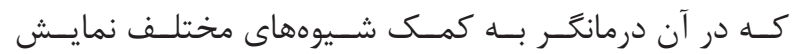

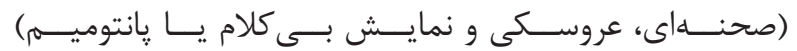

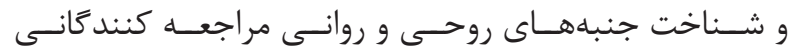

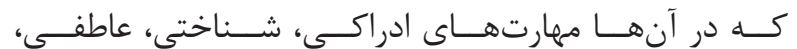

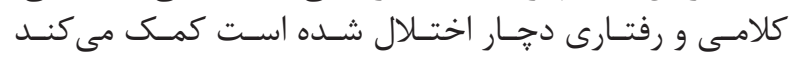

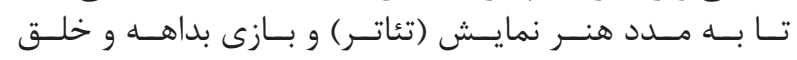

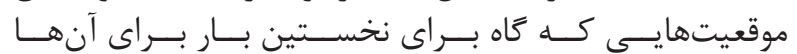

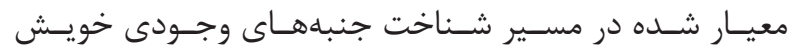

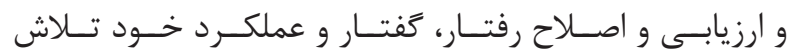

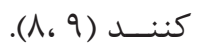

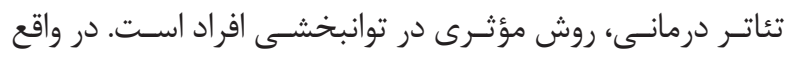

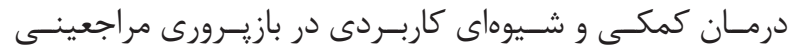

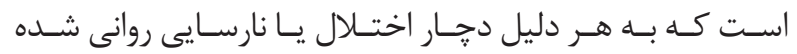

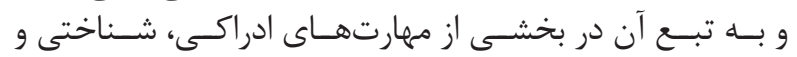

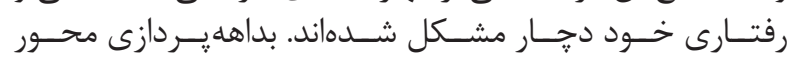

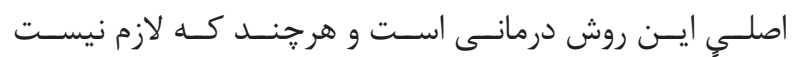

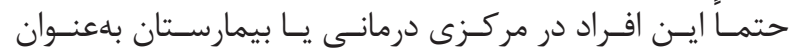

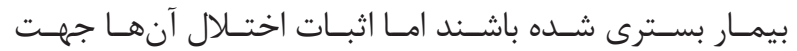

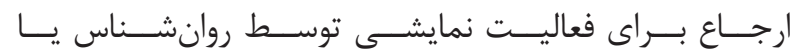

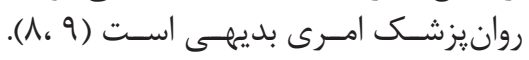

${ }^{4}$ Applied behavioral analysis

${ }^{5}$ Picture exchange communication system

${ }^{6}$ Teacch

${ }^{7}$ Psychodrama

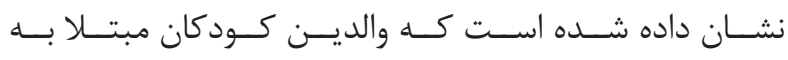

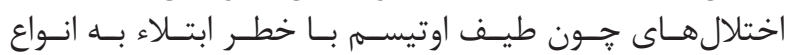

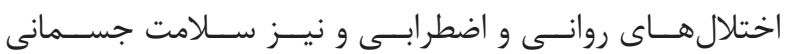

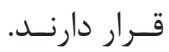

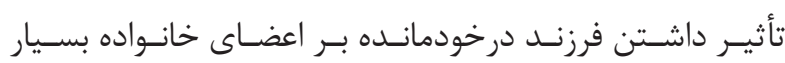

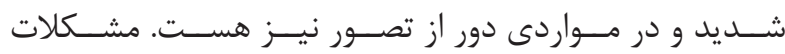

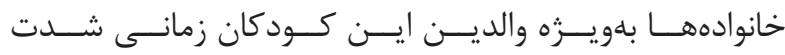

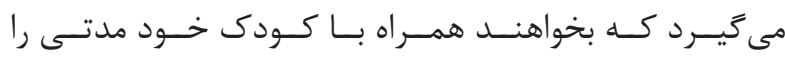

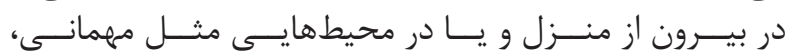

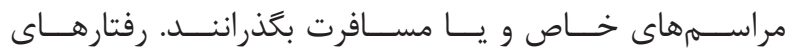

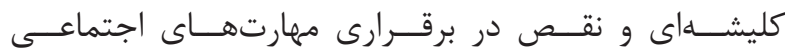

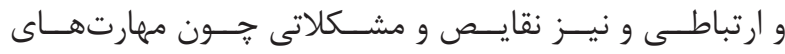

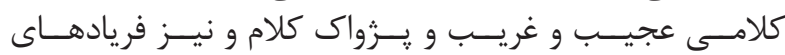

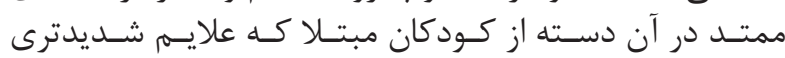

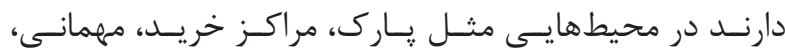

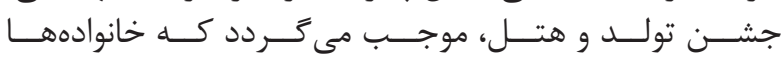

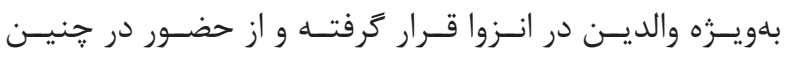

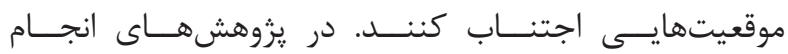

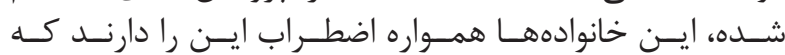

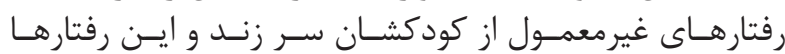

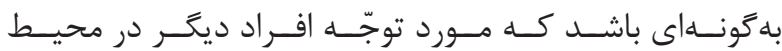

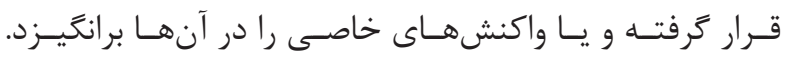

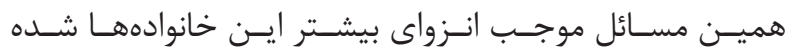

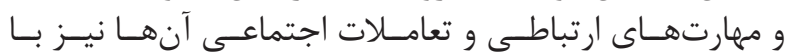

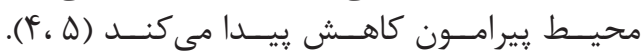

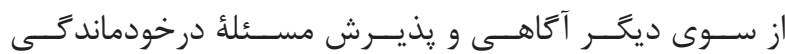

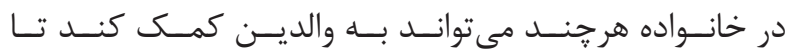

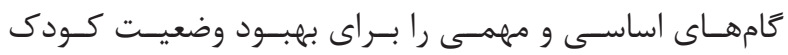

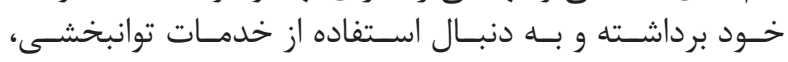

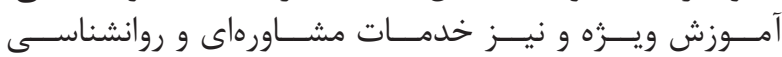

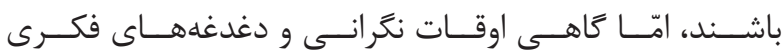

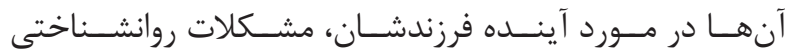

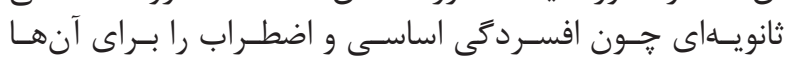

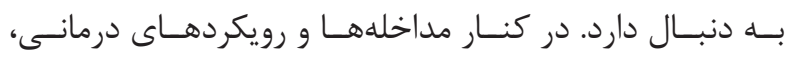

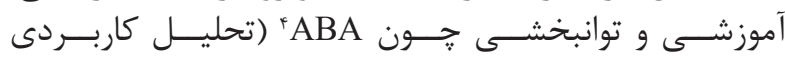

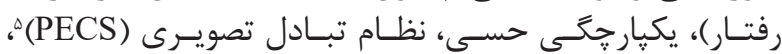

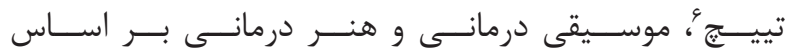

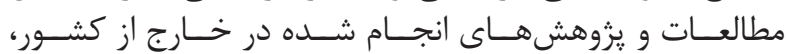

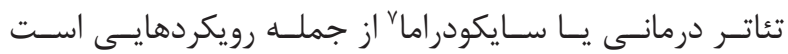

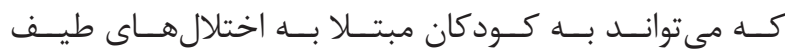

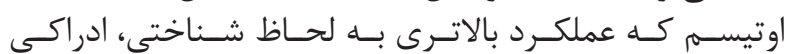

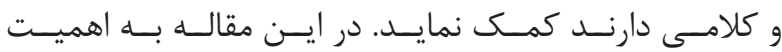

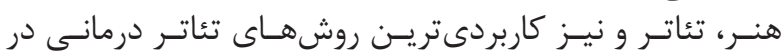

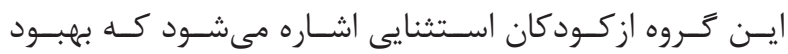
علايـهم اصلـى اختــلال را بـهـ دنبــال دارد (؟).

\footnotetext{
${ }^{8}$ Jones

${ }^{9}$ Ego

${ }^{10}$ Here and now
} 


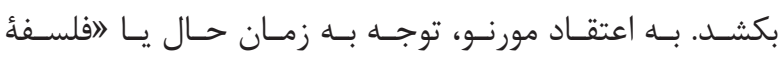

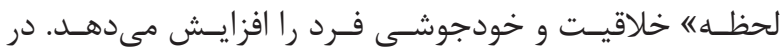

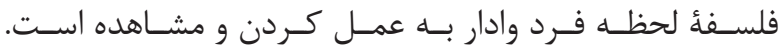

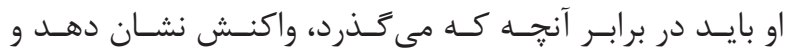

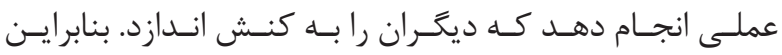

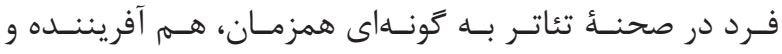

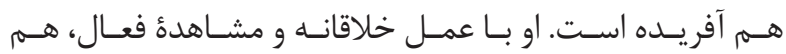

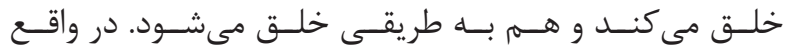

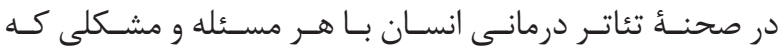

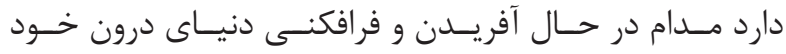

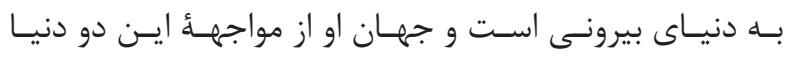

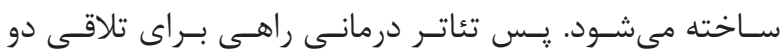

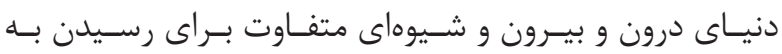

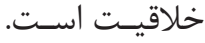

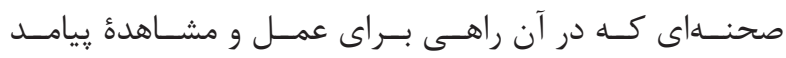

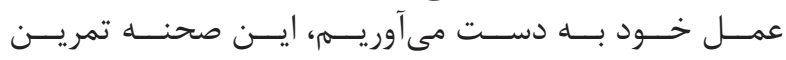

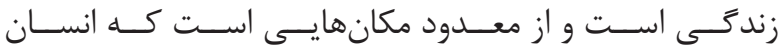

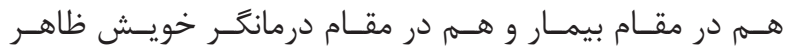

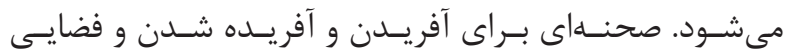

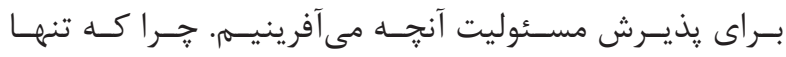

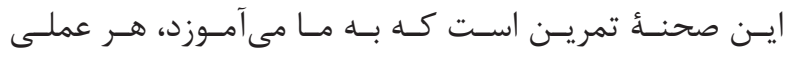

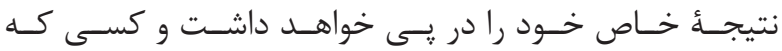

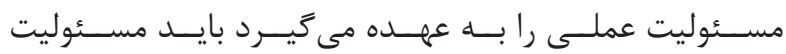

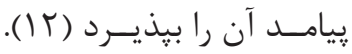

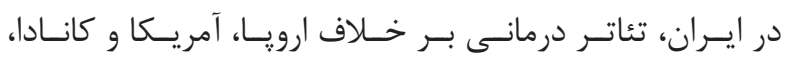

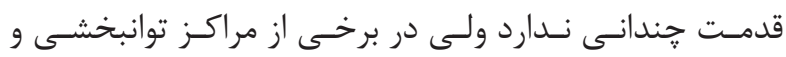

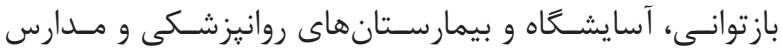

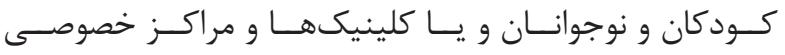

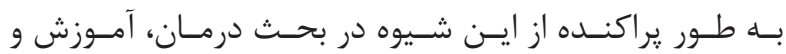

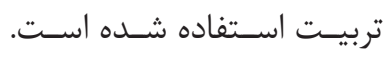

$$
\text { ويزگَى هاى درمانى و روانشناختى هنر تئاتر }
$$

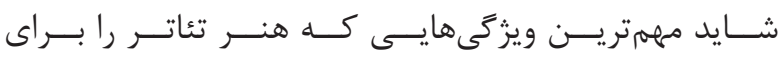

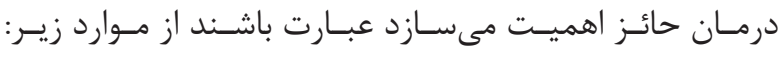

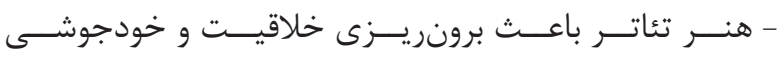

$$
\text { مى شــــود. }
$$

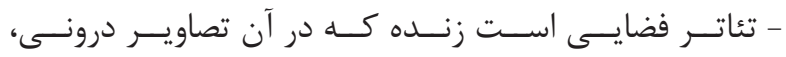

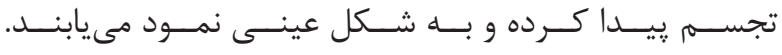

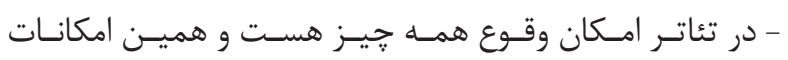

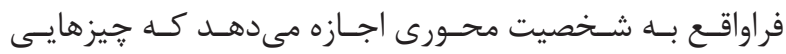

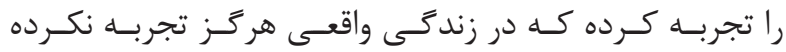

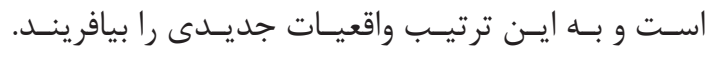

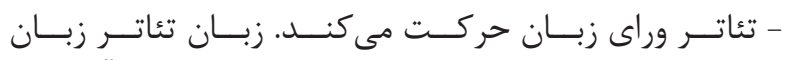

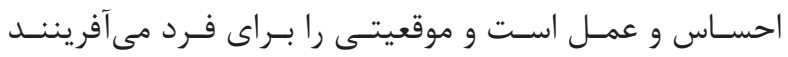

${ }^{11}$ Jacob. Lavy, Moreno

${ }^{12}$ Creativity
تاريخجُهُ نمايش درمانى (تئاتر درمانى)

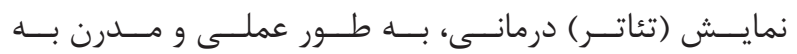

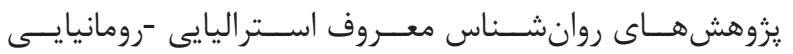

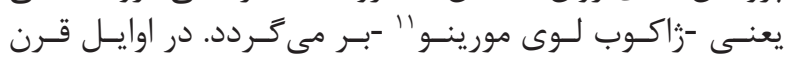

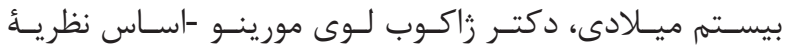

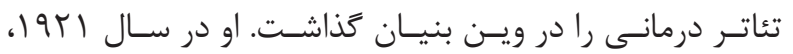

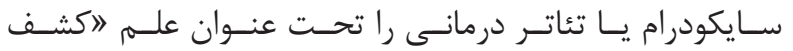

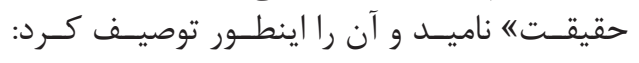

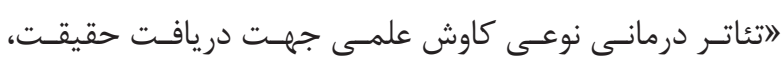

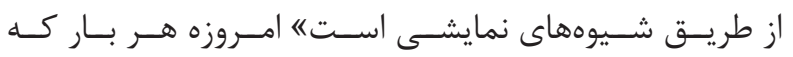

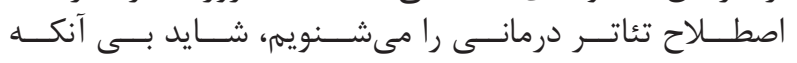

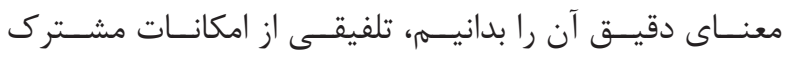

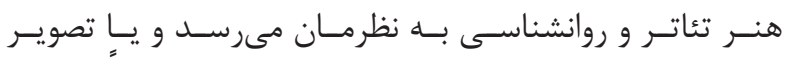

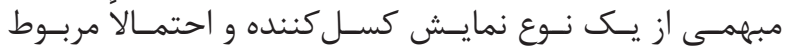

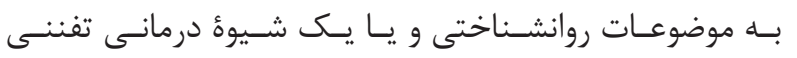

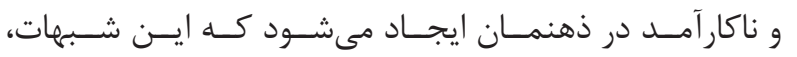

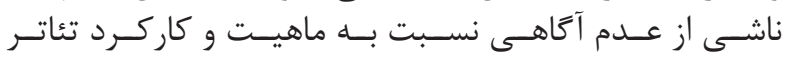

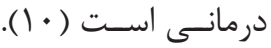

مورينـو، در تعريـف هـدف تئاتـــ درمانـى، كار خــود را با شـعار

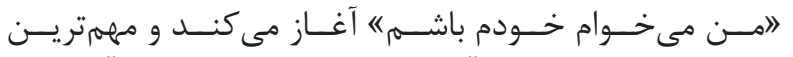

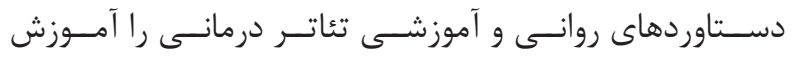

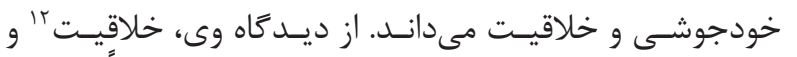

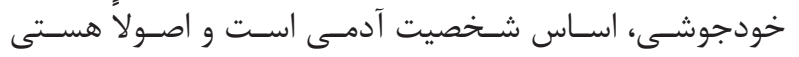

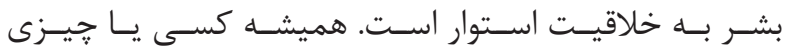

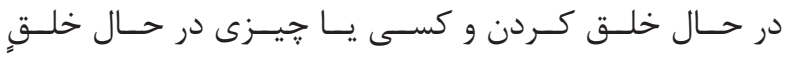

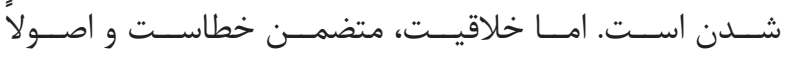

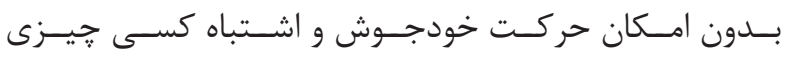

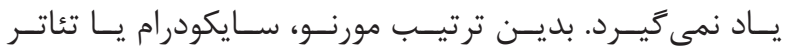

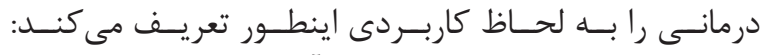

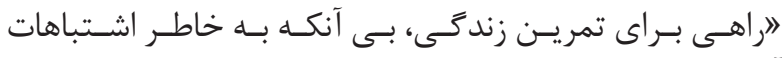

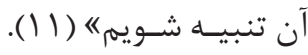
عناصر موجود در تناتر درمانى

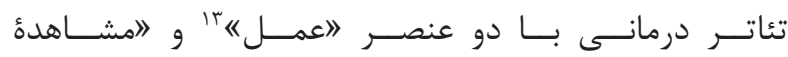

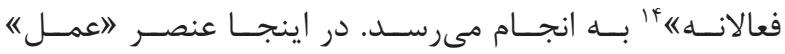

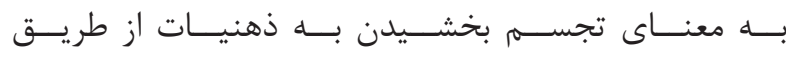

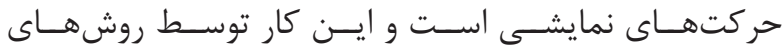

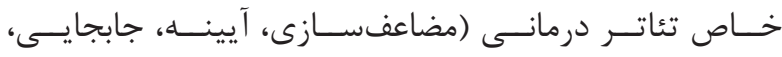

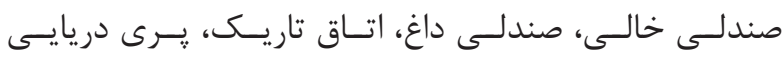

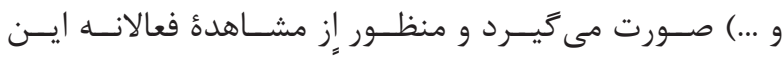

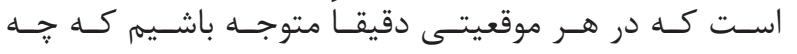

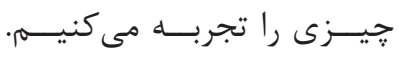

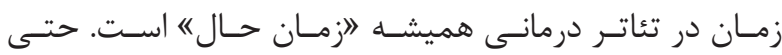

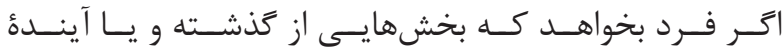

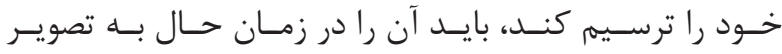

${ }^{13}$ Action

${ }^{14}$ Active observation 
- تقويت تماس خشمى با ديكر ان در خروه.

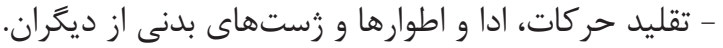
- تخلية عواطف، هيجانات و احساسات

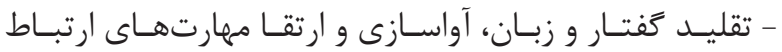

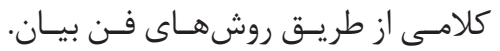

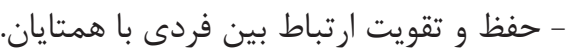

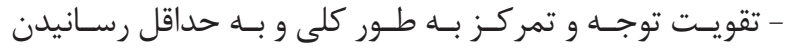

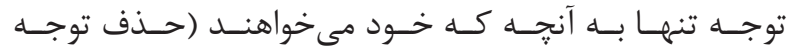

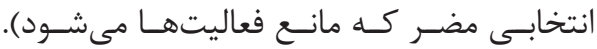

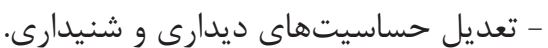

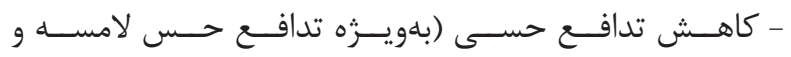
شــنـيدارى).

- بيرون آمدن از انزواطلبى و درخودماندكى.

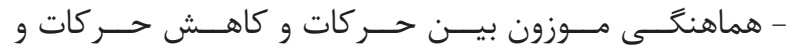

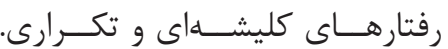

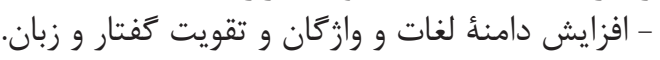

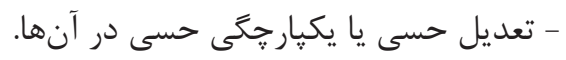

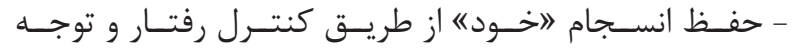

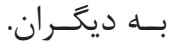

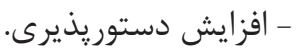

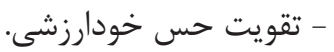

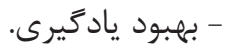

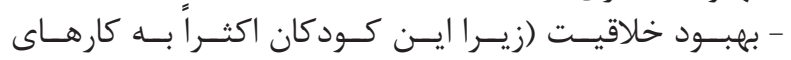

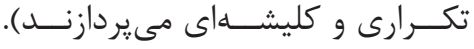
- تقويت توانايى حل مسئله.

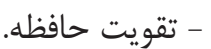

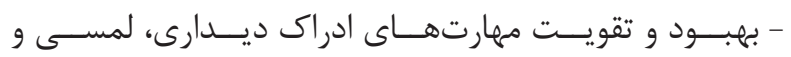

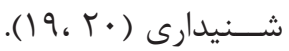

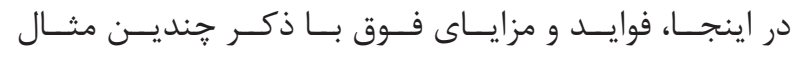

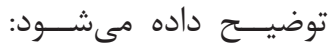

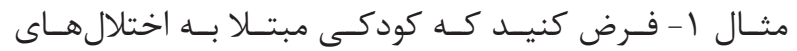

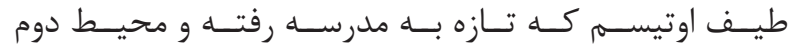

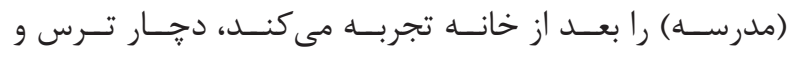

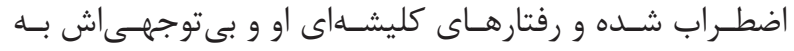

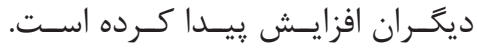

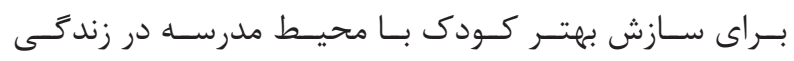

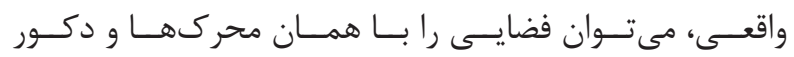

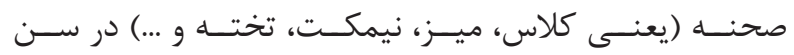

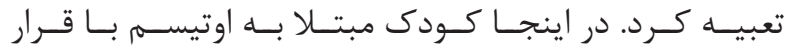

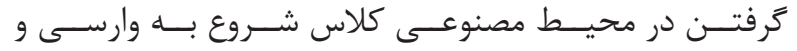

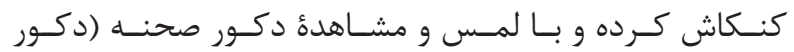

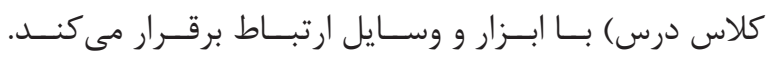

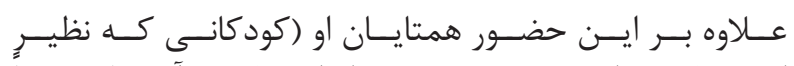

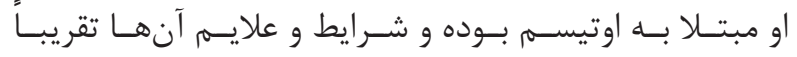

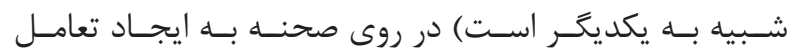

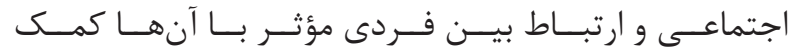

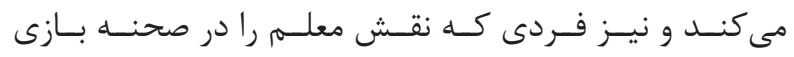

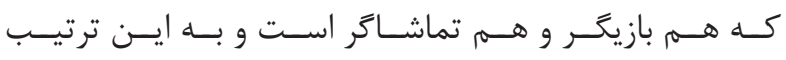

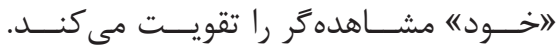

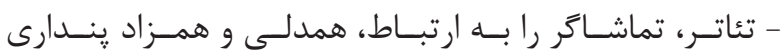

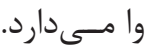

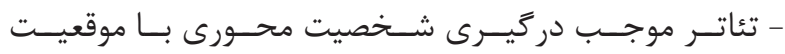

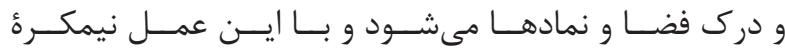

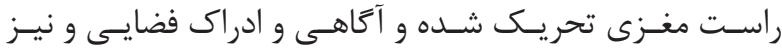

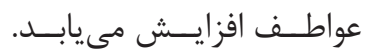

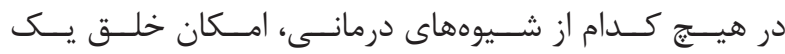

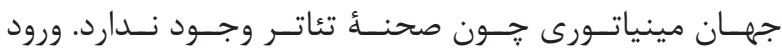

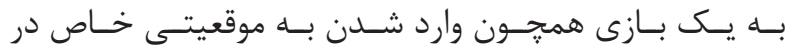

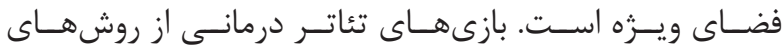

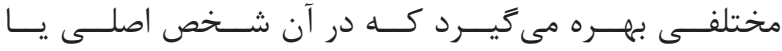

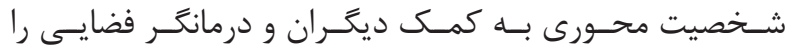

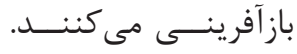

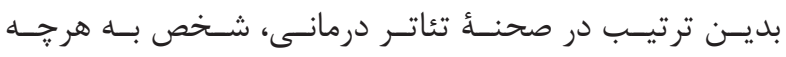

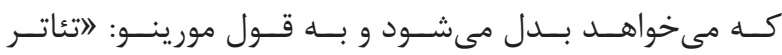

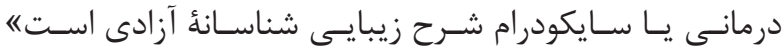

(IT، IF)

الهميــت تئاتـــر در كـــودكان و نوجوانــان مبتـــلا بــهـ

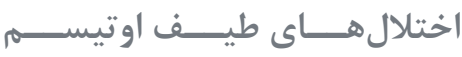

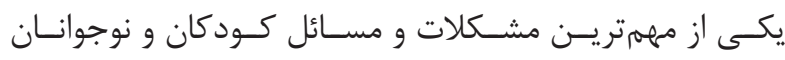

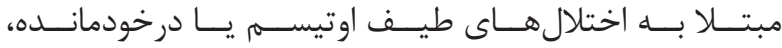

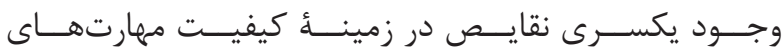

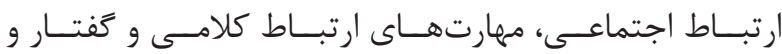

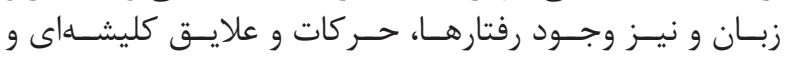

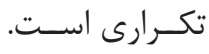

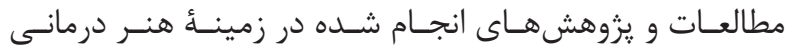

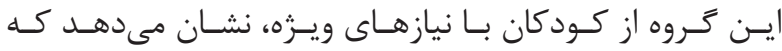

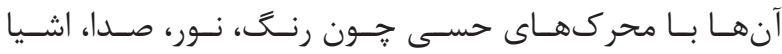

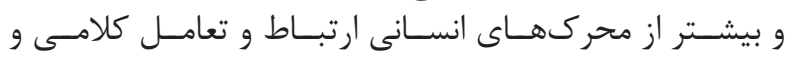

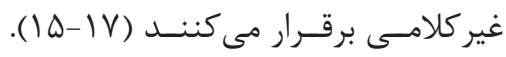

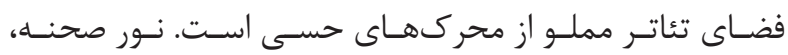

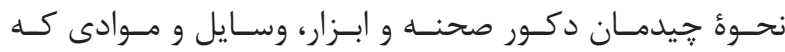

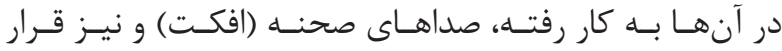

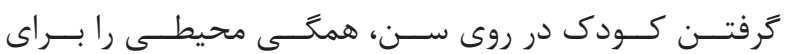

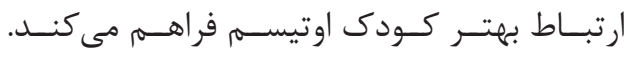

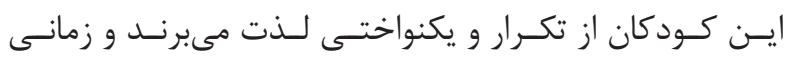

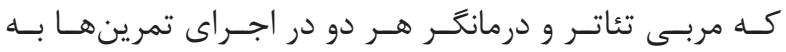

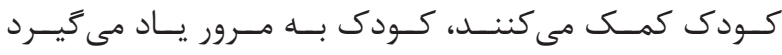

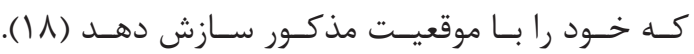

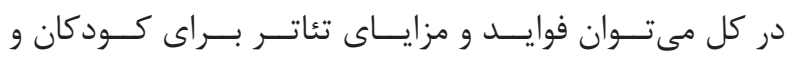

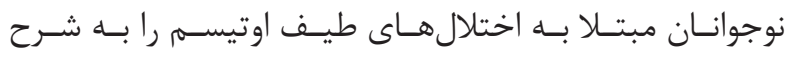
زيــر بيـان نمــود: 


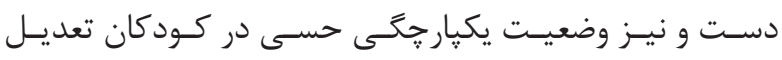

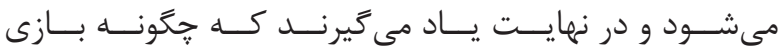
كنـــد.

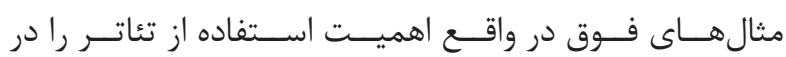

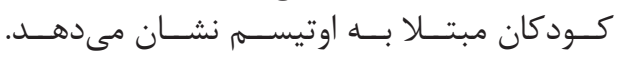

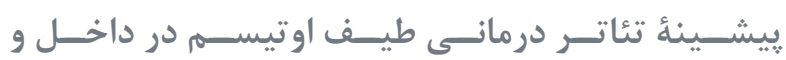

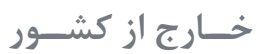

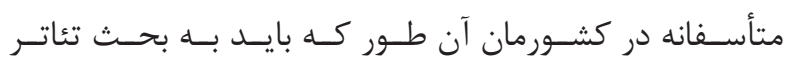

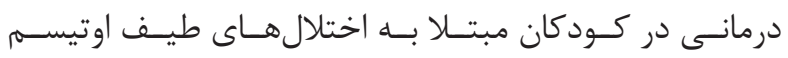

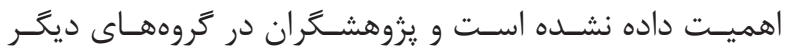

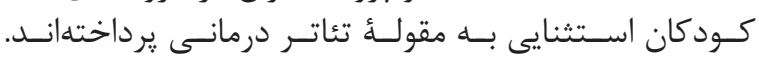

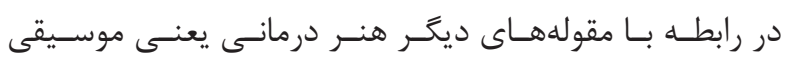

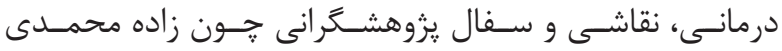

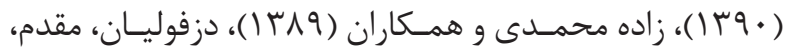

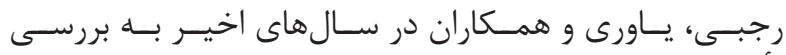

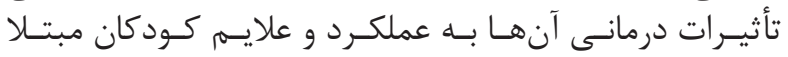

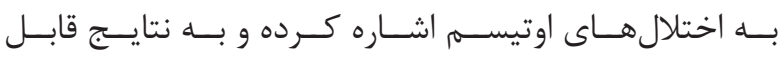

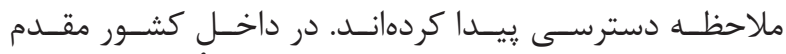

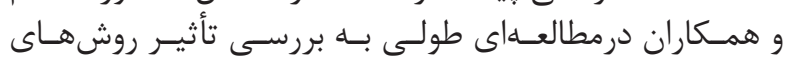

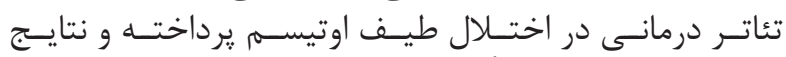

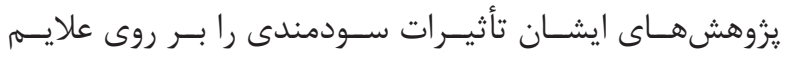

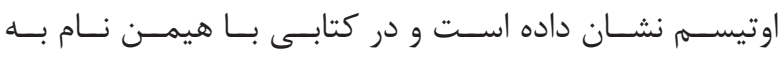

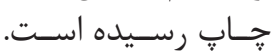

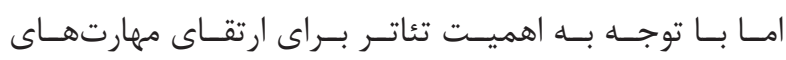

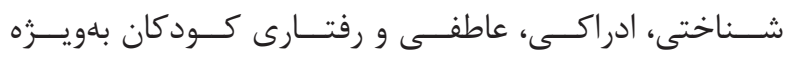

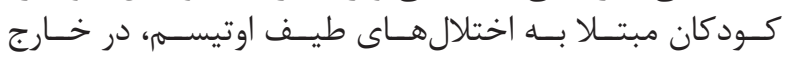

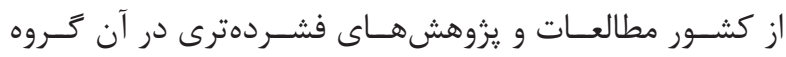

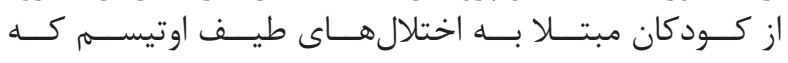

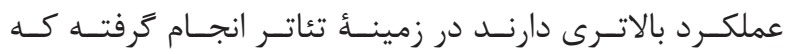

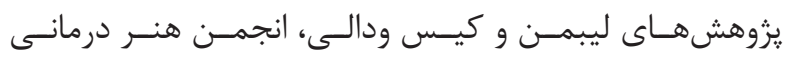

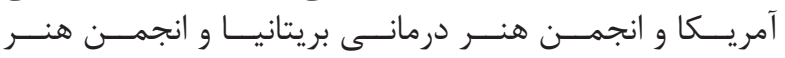

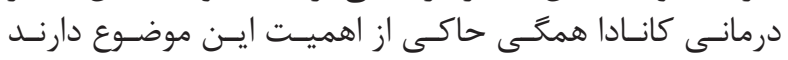

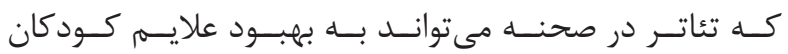

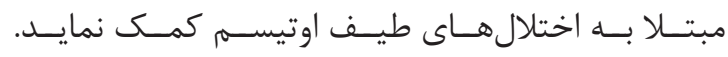

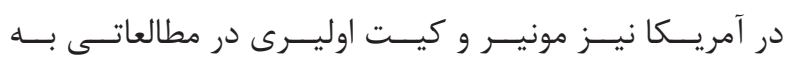

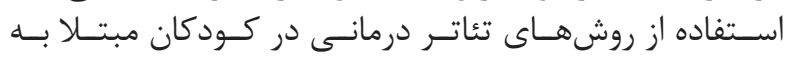

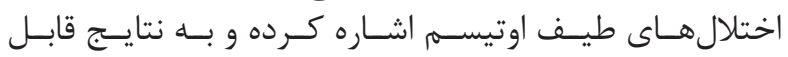

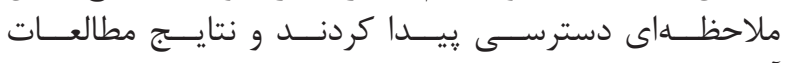

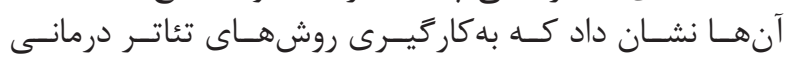

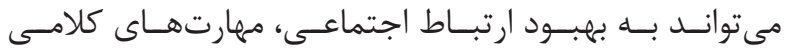

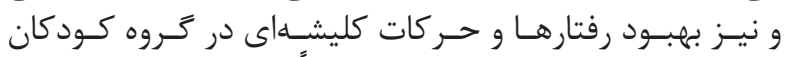

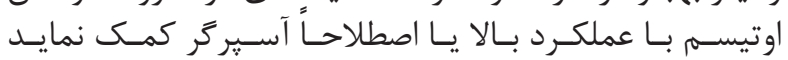

(YY, YQ)

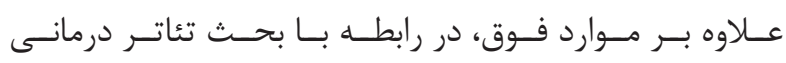

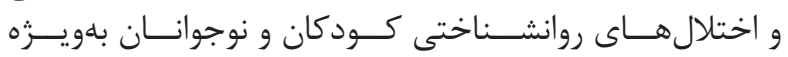

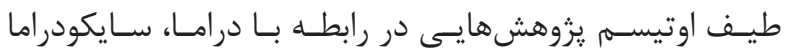

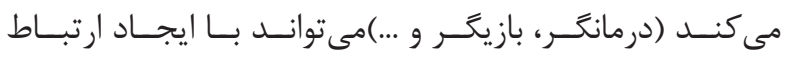

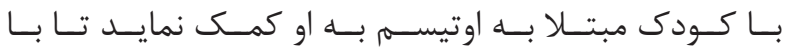

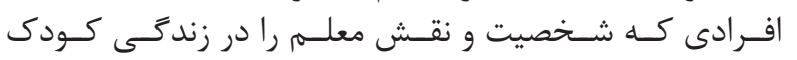

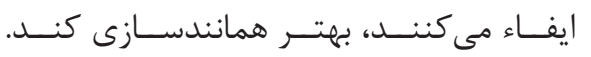

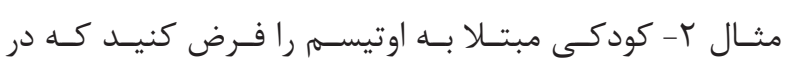

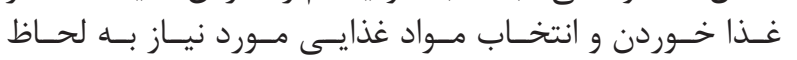

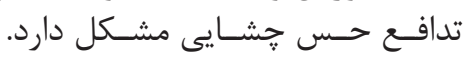

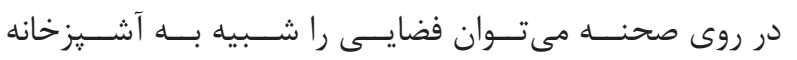

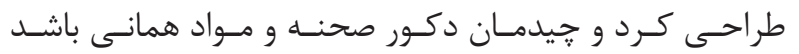

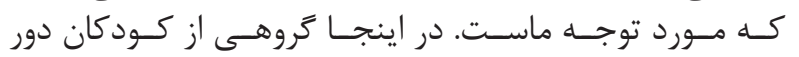

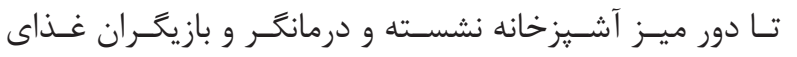

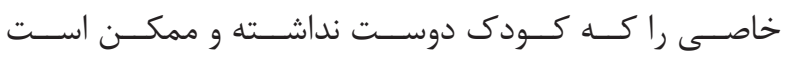

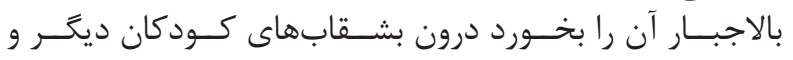

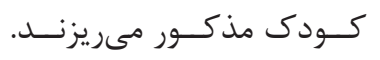

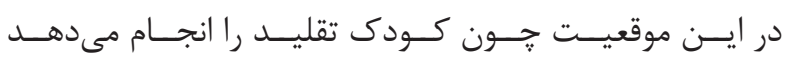

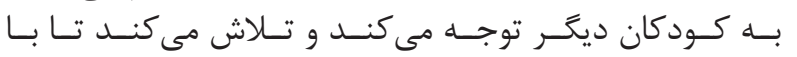

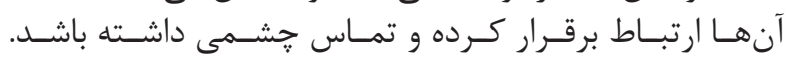

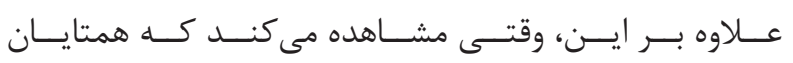

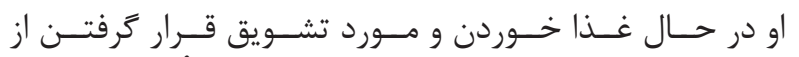

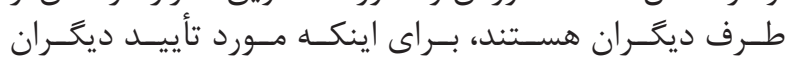

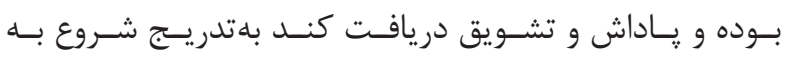

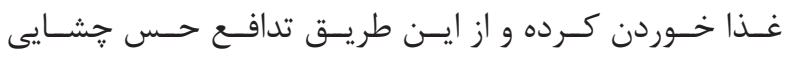

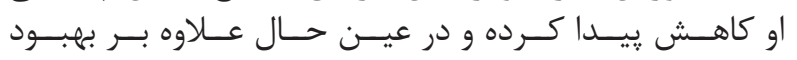

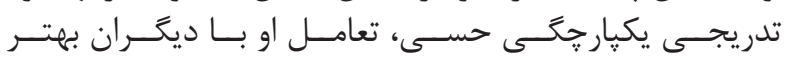

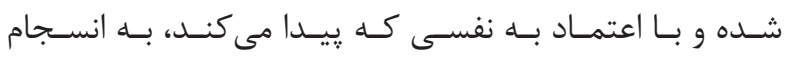

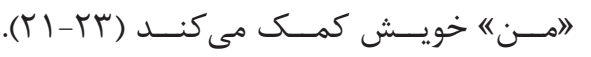

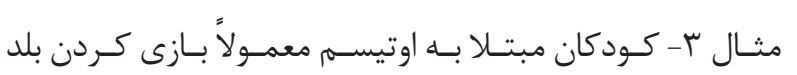

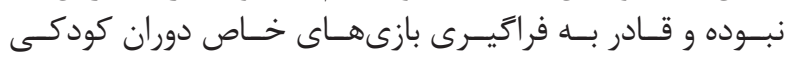

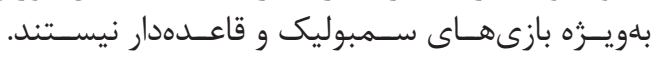

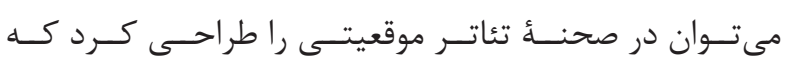

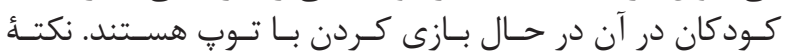

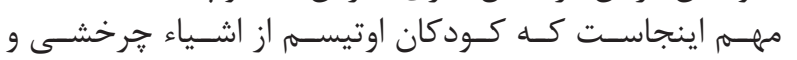

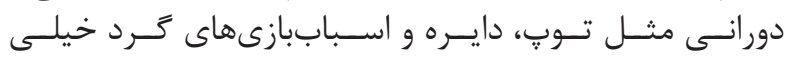

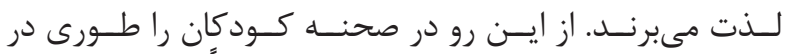

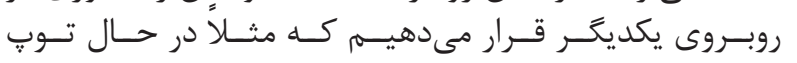

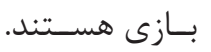

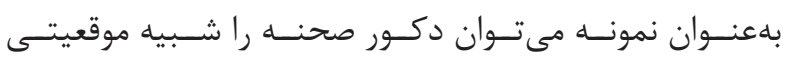

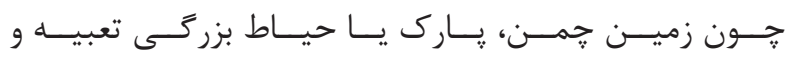

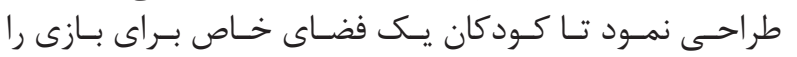

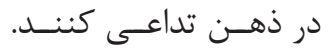

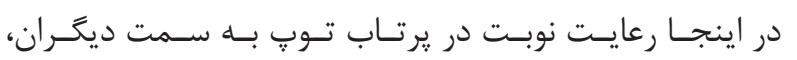

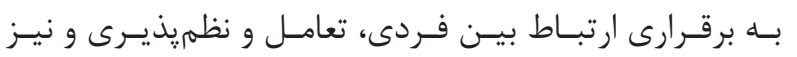

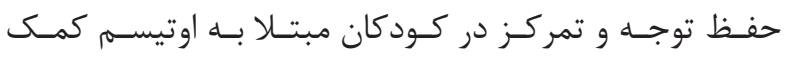
مى كنــد.

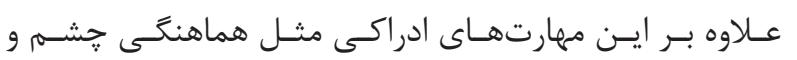


منســمم شـود. در مقايسـهُ تئاتـر درمانـى بـا ديخــر مداخـلات

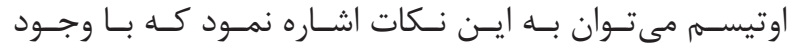

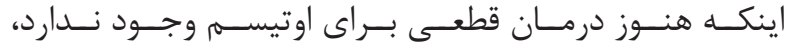

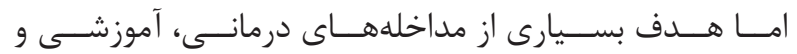

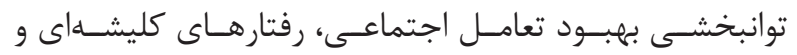

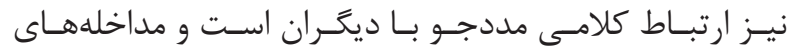

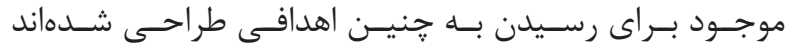

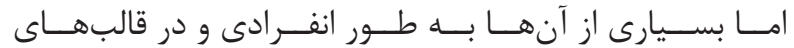

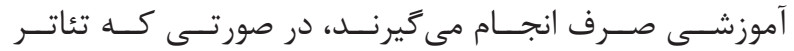

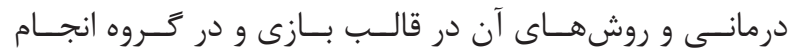

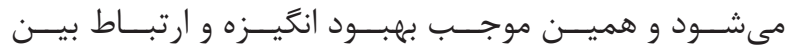

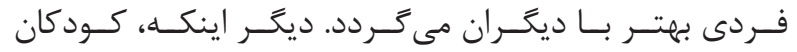

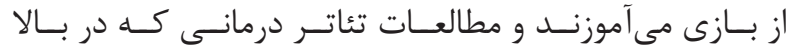

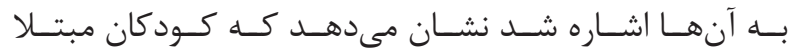

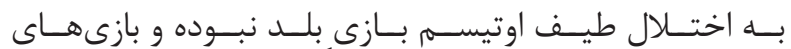

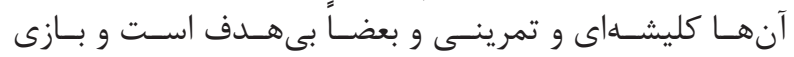

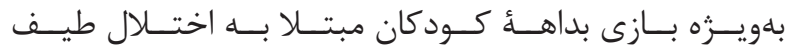

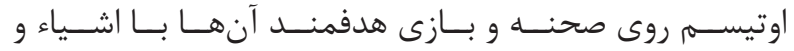

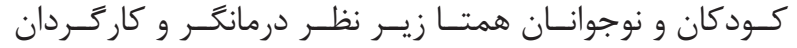

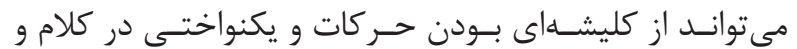

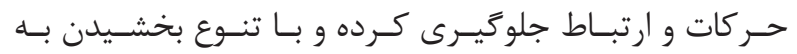

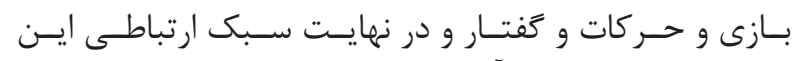

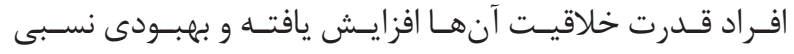

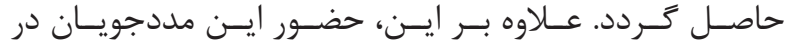

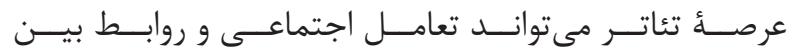

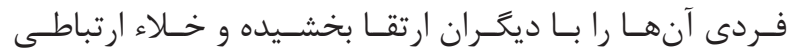

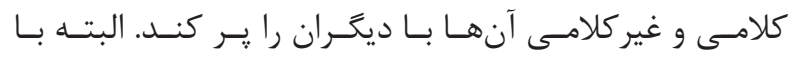

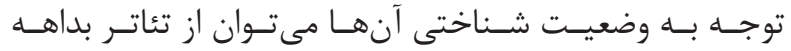

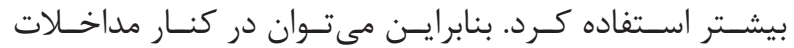

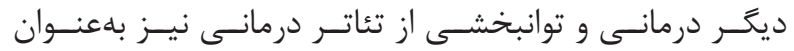

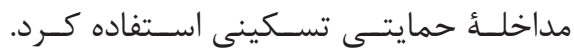

1. American art therapy association. »about art therapy«. http://www.arttherapy.org/aboutart.html.2009.

2. Autism society of american. newsletter. http://www. Autim Society.org. 2006.

3. Autism society of America. Newsletter. http://www. autism-society.org. 2013.

4. Autism society of America. Newsletter. http://www. autisms society. org. 2012.

5. Autism society of America. Newsletter. http://www. autisms society. org. 2014.

6. Case C, Dalley T. »Art therapy with children from infancy to adolescence«. USA \& UK: Newyork \& London: Routledge. 2008; p. 46-47.

7. Case C, Dalley T. Working with children in art

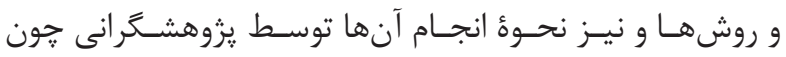

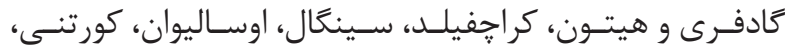

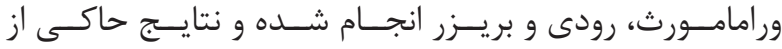

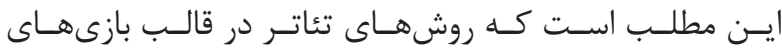

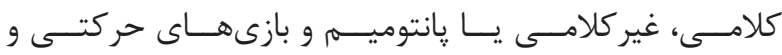

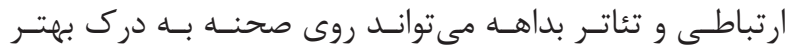

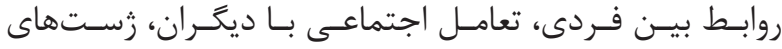

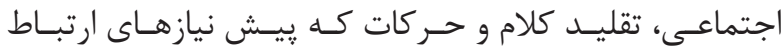

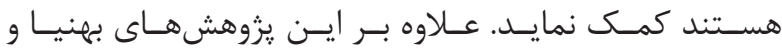

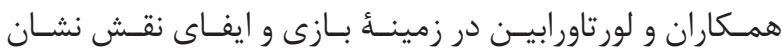

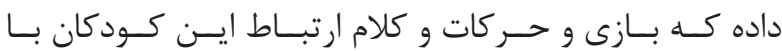

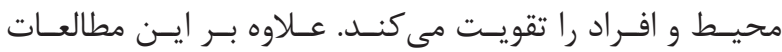

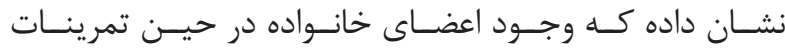

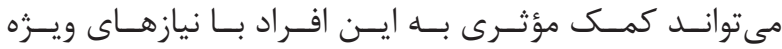

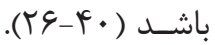
نتيجه گيرى

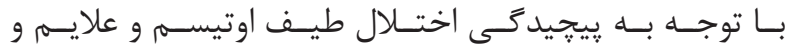

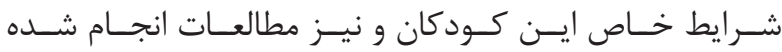

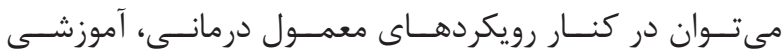

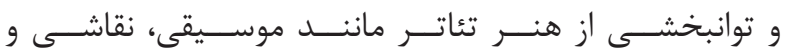

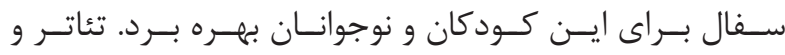

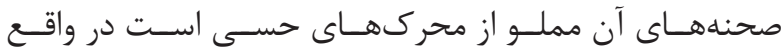

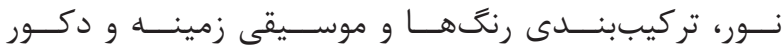

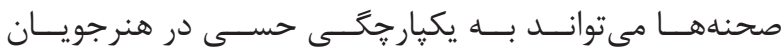

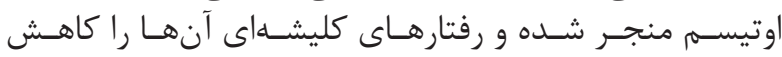

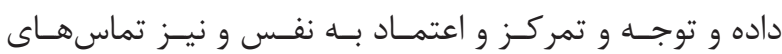

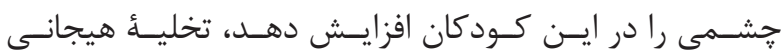

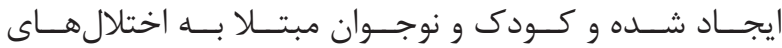

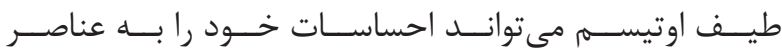

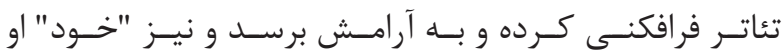

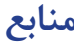

therapy. $2^{\text {nd }}$ Ed. London: Rutledge. 2006; p. 80.

8. Case C, Dalley T. The handbook of art therapy. 2nd ed. London: Routledge. 2006; p. 58-60.

9. Amraee M. Ten step with psychodrama. Tehran. Tahoora Publication. 2010; p. 20-4.

10. Amraee M. Theatre therapy. Tehran: Danjeh Publication. 2011; p. 30-6.

11. Akbari M. Theatre therapy and its contents related to mental improvement of injuries of natural accidents. m.a thesis of dramatic literatures. Theran: Islamic Azad University. Central Tehran Branch. Faculty of Art. 2008.

12. Jones Ph. Theatre therapy and life drama. yasrebi chista. Tehran: Ghatreh Publication. 2004.

13. Darivasi E. The effectiveness of psychodrama on 6 
years old children with behavioral disorders of morvarid kindergarten of neka. Golestan University of Researches and Sciences. 2015.

14. Rajabi Behjat B. Design and evaluation of art therapy program on improvement of social interaction of autistic students between 6-12 years old. Tehran. Alzahra University, Faculty of Psychology. 2011.

15. Zadeh Mohammadi A. Art therapy, an introduction to art therapy for groups. Tehran, Ghatreh Publication. 2010; p. 28-30.

16. Zadeh Mohammadi A. Integration -centered art therapy: an iranian approach. The $3^{\text {rd }}$ ed. National Art Therapy Congerss. Tehran, Shahid Beheshti University. Centre of Art Therapy Studies. 2011.

17. Samadi SA. McKoncy R. Autism spectrum disorders. Tehran: Doran Publication. 2011; p. 10.

18. Samadi SA. Children with autism: educational guidance for parents and trainers. Tehran. Doran Publication. 2013; p. 12-4.

19. Kianian D. Children and adolescent's theatre for trainers. Tehran. Cultural Institute of Monadi Tarbiat. 2006; p. 33-6.

20. Kianian D. Children theatre. Tehran, Cultural Institute of Monadi Tarbiat. 2005; p. 68.

21. Ganji M. Mental psychopathology according to DSM V. The 3 rd ed. Tehran, Savalan Publication. 2013; p. 68-72.

22. Liebman M. Art therapy speciality for groups. Zadeh Mohammadi Ali. Tehran, Ghatreh Publication. 2010. p. 80-2.

23. MoghaddamK. Design and evaluation of familycentered art therapy program on marital satisfaction, verbal skills, social interactions and stereotypical behaviors of children with autism spectrum disorders. PhD Dissertation. Tehran. University of Researches and Sciences. Faculty of Humanities and Social Sciences. 2015.

24. Moghaddam K. Psychodrama in children and adolescents with autism spectrum disorders. Tehran. Vania Publication. 2016; p. 28-34.

25. Moghaddam K. Psychodrama adolescents with autism spectrum disorders. Tehran. Vania Publication. 2016; p. 54.

26. Emma G, Deborah H. Benefits of dramatherapy for autism spectrum disorder: a qualitative analysis of feedback from parents and teachers of clients attending roundabout dramatherapy sessions in schools.
Dramatherapy. 2013; 35(1): 20-8.

27. Crutchfield C. Drama therapy is a new tool to help those with autism. http://spokesman-recorder.com/2017/11/24/ drama-therapy-new-tool-help-autism/.2017.

28. Singal S. The efficacy of psychodrama in the treatment of oppositional and defiant adolescents. Department of educational and counselling psychology McGill University. Montreal. 2016.

29.Carmel O'Sullivan. Drama and autism. Trinity College, University of Dublin, Dublin, Ireland. 2015.

30. Brazier Y. Drama therapy: Unlocking the door to change, Medical News Today. 2016.

31. Meyer DD. Drama therapy as a counseling intervention for individuals with eating disorders. http:// counselingoutfitters.com/ vistas/vistas10/ Article-08. pd. 2010 .

32. Bouzoukis CE. Pediatric dramatherapy: they couldn't run, so they learned to fly. London: Jessica Kingsley Publishers. 2001.

33. Adler JM. Living into the story: agency and coherence in a longitudinal study of narrative identity development and mental health over the course of psychotherapy. J Pers Soc Psychol. 2012; 102(2): 367-89.

34. Jo Rudy L. How drama therapy can help people with autism. Verywell Health Newsletter. https://www. verywellhealth.com/how-can-drama-therapy-helppeople-with-autism-260295. 2018.

35. Schneider C. Acting antics. London: Jessica Kingsley Publishing. 2007.

36. Wheater C. "Theatre therapy for children with autism”. Education Masters. 2013; p. 265.

37. Maynard K. Dramatherapy: history, applications and outcome measures. The Association of Child and Adolescent Mental Health. https://www.acamh.org/blog/ dramatherapy-his tory-applications-outcome-measures/. 2018.

38. Ramamoorth P. Autism spectrum and the theater. The Art of Autism. 2016.

39. Loretta GL, Lawrence C R. Play-based interventions for children and adolescents with autism spectrum disorders. Routledge, Taylor \& Francis Group. 2012; p. 397.

40. Behnia F, Rassafiani M, Nakhai S, Mohammadpour M, Ahmadi Kahjoogh M. Time use of mothers of children with an autism spectrum disorder: a comparative study. Iranian Rehabilitation Journal. 2017; 15(1): 49-56. 